\title{
Ageing effect of vegetable oils impregnated paper in transformer application
}

\begin{abstract}
Vegetable oils are being considered as potential alternatives to mineral oil, due to their better environmental performance and for their high fire point. Although these liquids have been used in distribution transformer, it is still a significant step to adopt vegetable oils in power transformer due to high cost and high level of safety and reliability required in service for these units. Vegetable oils such as Palm oil (PO), Corn oil (CO), and Rice Bran oils (RBO) offer suitable alternative for mineral oil. It is anticipated that most of the un-aged oil could satisfy the minimum requirement for dielectric insulation liquids in transformer. However, since transformers in service could be subjected to heat and multiple environmental parameters, the oil could be subjected to ageing. The chemical properties of the oil may change and its performance could be affected by the presence of ageing-by-products such as moisture and acids. Therefore, considering the application of new dielectric insulation liquids such as $\mathrm{PO}, \mathrm{CO}$ and $\mathrm{RBO}$ in transformer, it is crucial to first examine its ageing performances at laboratory level. This paper focused on the effect of ageing on the electrical and physicochemical properties of $\mathrm{PO}, \mathrm{CO}$, and $\mathrm{RBO}$. Sealed ageing experiments were set at $90^{\circ} \mathrm{C}$ for 30 days, 90 days and 180 days. Before the ageing process, the samples were dried in a vacuum oven at pressure less than $0.8 \mathrm{kP}$ at $85^{\circ} \mathrm{C}$ for 48 hours in order to remove the moisture content in the oils. Then the oils were impregnated with the Kraft paper and continue to age for selected duration time. The electrical properties (relative permittivity, dielectric losses, resistivity and breakdown strength), mechanical properties (viscosity and tensile strength) and chemical properties (moisture and acidity) of the oils were measured throughout the ageing periods. It can be concluded that the laboratory accelerated thermal ageing experiment reveals that all vegetable oils in this study are resistant toward oxidation based on the stable viscosity and low acidity measurements of vegetable oils throughout the ageing duration even with the presence of oxygen. The AC breakdown voltages of vegetable oils can still comply with the recommended limit of new vegetable oil set by ASTM 6781 even after subjected to ageing. In general most of properties of vegetable oils are comparable with mineral oil.
\end{abstract}

Keyword: Vegetable oils; Ageing; Electrical properties; Mechanical properties; Chemical properties 